\title{
An unusual bullous reaction in borderline leprosy
}

\author{
K SINGH \\ Department of Dermatology \& Venereology, All India Institute of \\ Medical Sciences, Ansari Nagar, New Delhi-110029, India*
}

Accepted for publication 15 April 1986

\begin{abstract}
Summary A 45-year-old male patient suffering from borderline lepromatous leprosy with reaction, developed round or irregular, well defined, large tense bullae on existing leprosy lesions. There was deposition of $\operatorname{IgG}, \operatorname{IgM}, \operatorname{IgA}$ and fibrin along the basement membrane. It was not a bullous drug eruption due to either rifampicin, dapsone or clofazimine, but a component of leprosy reaction. Difficulties in classifying as either Type I or Type II reaction are discussed.
\end{abstract}

\section{Introduction}

Bullous eruptions are rarely observed in leprosy patients. Generalized bullous drug eruptions due to rifampicin ${ }^{1}$ and $\mathrm{DDS}^{2}$ have been reported. Vesicles and bullae have been observed in purpuric, tender erythematous plaques of Lucio phenomenon and in the evanascent, tender erythematous skin nodules called erythema nodosum leprosum (ENL) lesions which may occur as a part of Type II leprosy reactions. ${ }^{3}$

Type I leprosy reactions occur in borderline leprosy. Existing lesions become more red and oedematous. Systemic disturbances are rare, though the patients may develop oedema of hands, feet or face. On the other hand in Type II reactions, seen in borderline lepromatous (BL) and lepromatous leprosy (LL), systemic disturbances are usual and ENL lesions may occur, but there is no change whatsoever in the appearance of leprosy lesions. ${ }^{3}$

\section{Case report}

A 45-year-old, male, gave a 4-year history of a progressively enlarging hypopigmented hypo-aesthetic patch over the left side of the chest and a

* Present address: Farasan General Hospital, Farasan, Gizan, Kingdom of Saudi Arabia 
stationary patch over the left thigh. Two months earlier, he had suddenly developed multiple erythematous plaques over the body, paraesthesia over hands, forearms, shins and face, oedema of hands and feet and pain in wrist and ankle joints. This was not associated with fever, malaise or drug intake.

On examination, there were numerous, asymmetrically, distributed, raised erythematous, plaques with smooth stretched surface and gradually sloping borders. The margins were indistinct in places. Two of these plaques were large, being $12 \mathrm{~cm}$ in diameter, whereas most others were small, varying between 1 and 3 $\mathrm{cm}$ in diameter. Hair loss and hypo-aesthesia were noted only in the larger lesions. There was glove and stocking type of anesthesia. Ulnar, lateral popliteal and radial nerves on both sides were thickened and tender. Axillary and inguinal lymph nodes were enlarged, discrete, mobile and non-tender. Oedema of hands and feet was gross. Systemic examination was unremarkable.

Investigations revealed $\mathrm{Hb} 13.2 \mathrm{gm} \mathrm{dl}^{-1}$, total leukocyte count $5200 \mathrm{cu} \mathrm{mm}^{-1}$, neutrophils $60 \%$, lymphocytes $32 \%$, eosinophils $4 \%$, monocytes $4 \%$ and erythrocyte sedimentation rate by Westergrens method was $23 \mathrm{~mm}$ in one hour. No abnormality was detected in urine and stool examination. Blood chemistry revealed random glucose $60 \mathrm{~g} \mathrm{dl}^{-1}$, urea $16 \mathrm{mg} \mathrm{dl}^{-1}$, creatinine $1.4 \mathrm{mg} \mathrm{dl}^{-1}$, sodium $140 \mathrm{mEq} \mathrm{L}^{-1}$, potassium $3.4 \mathrm{mEq} \mathrm{L}^{-1}$, albumin $3.6 \mathrm{~g} \mathrm{dl}^{-1}$, globulin $4.3 \mathrm{~g}$ $\mathrm{dl}^{-1}$, total bilirubin $1.6 \mathrm{mg} \mathrm{dl}^{-1}$, alkaline phosphatase $3.3 \mathrm{IU} \mathrm{dl}^{-1}$, glutamic oxaloacetic transaminase 60 units $\mathrm{ml}^{-1}$ and glutamic pyruvic transaminase 45 units $\mathrm{ml}^{-1}$. Chest X-ray examination was normal. Histopathology of lesions revealed normal epidermis, a Grenz zone and loose foamy macrophage granulomas scattered throughout the oedematous dermis. There were numerous lymphocytes and occasional foreign body giant cells. Nerves had onion-skin perineurium. Ziehl-Neelsen staining showed numerous $(5+)$ granular acid-fast bacilli (AFB).

At this stage the patient was thought to have BL leprosy in Type I reaction. He was put on multidrug regimen with rifampicin $600 \mathrm{mg}$, clofazimine $300 \mathrm{mg}$, DDS $100 \mathrm{mg}$ and prednisolone $30 \mathrm{mg}$ daily. The reaction subsided mildly over the first few days, but worsened between the 12th to 14th day. At this time numerous, round to irregular, well defined, tense bullae measuring 5-20 $\mathrm{mm}$ in diameter appeared over all the leprosy lesions (Figures 1 and 2). Most of them contained clear fluid though some were haemorrhagic. A few small lesions occurred over soft palate.

The patient was hospitalized and repeat haemogram and blood chemistry done at this time were essentially similar to that at presentation. However improvement of liver function tests was observed. The bulla fluid contained polymorphs and occasional eosinophils. Acantholytic cells and AFB were not seen. Histopathology of the bulla (Figures 3-6) showed a location in the subepidermis. It contained fibrin, neutrophils, red blood cells (RBC) and occasionally plasma cells and eosinophils but no acantholytic cells. At the base of bulla and in the dermis, there were foamy macrophage granulomas, with a few 


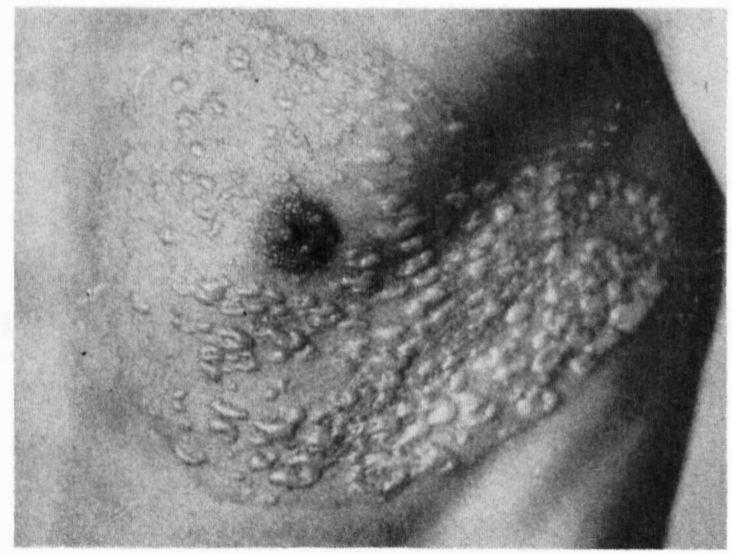

Figure 1. Irregular, large and tense bullae confined strictly to the plaque on left side of chest.

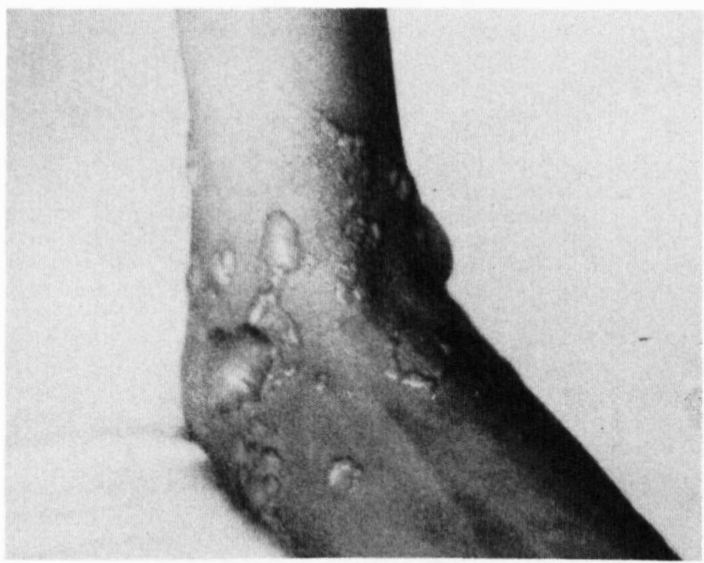

Figure 2. Bullae confined to leprosy lesion on left forearm.

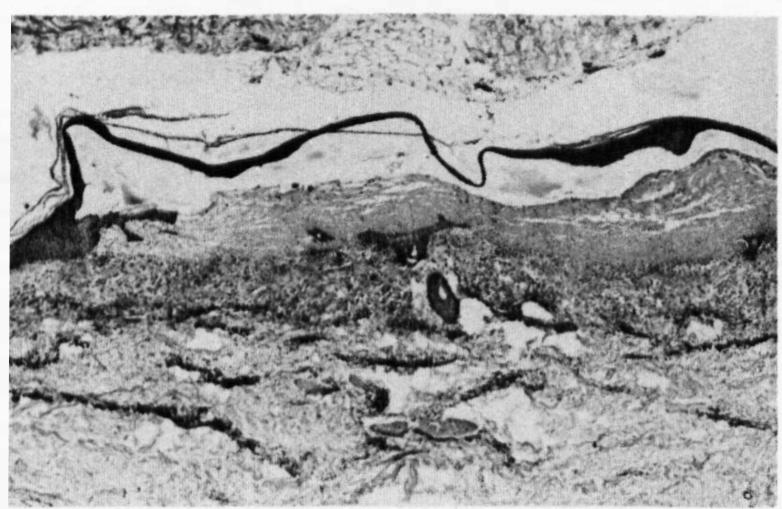

Figure 3. Large subepidermal bulla with slight regeneration of epidermis. Diffuse and loose granuloma at the base. Infiltrate along neurovascular bundles and around adnexa in deeper dermis $(\mathrm{H} \& \mathrm{E} \times 25)$. 


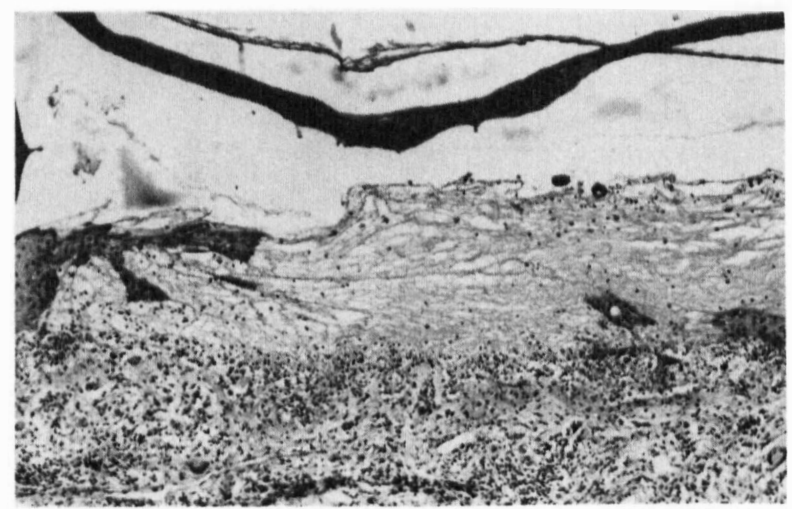

Figure 4. Marked oedema of upper dermis and fibrin deposition. Dilated vascular spaces. Dense infiltrate with few langhan giant cells $(\mathrm{H} \& \mathrm{E} \times 72.5)$.

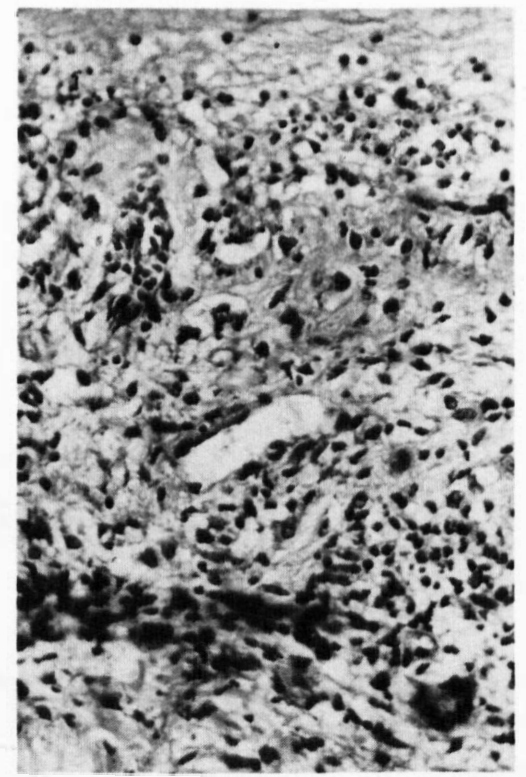

Figure 5. Dilated vessels, extravasation of RBC, neutrophiles, nuclear dust, lymphocytes, langhan giant cells, vacuolated macrophages and oedema of dermis at the base of bulla $(H \& E \times 250)$.

epithelioid cells and lymphocytes, occasional Langhans and foreign body giant cells. Significantly the granuloma was heavily infiltrated by neutrophils, some showing karyorrhexis, with a few eosinophils and plasma cells. There was mild extravasation of RBCs. AFB were $2+$ and fragmented. At the edge of bulla, indirect immunofluorescence of cryostat sections showed positive staining for IgM, IgG, IgA and fibrin but no $\mathrm{C}_{3}$ along the basement membrane.

At this time, antileprosy drugs were stopped, while prednisolone was 


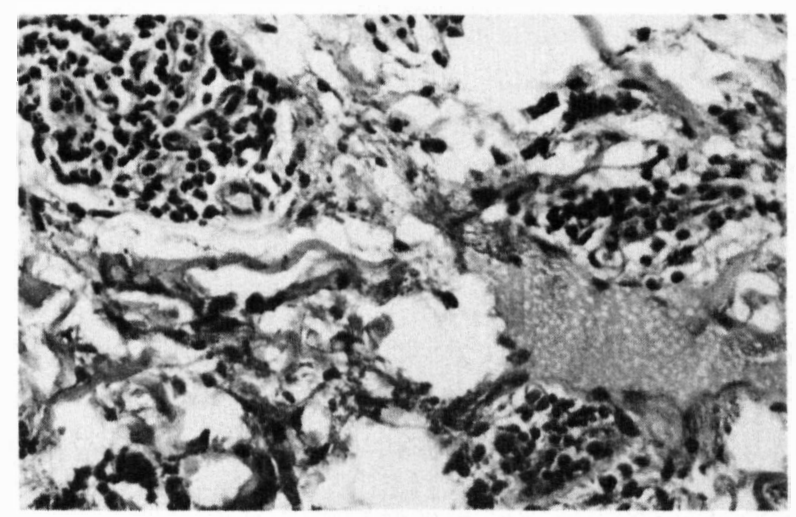

Figure 6. Infiltrate of vacuolated macrophages, lymphocytes, neutrophils along neurovascular bundles in lower dermis $(H \& E \times 250)$.

increased to $60 \mathrm{mg}$ per day. Within 3 days the bullous eruption was controlled and the patient improved gradually. By 4 weeks prednisolone could be reduced to 10 $\mathrm{mg} / \mathrm{day}$. In the $3 \mathrm{rd}$ and 5 th week the patient developed occasional small bullae along with mild exacerbation of reaction. They subsided spontaneously without any further treatment. Histopathology of bullae were identical to that examined at the time of hospitalization.

During the 6th week provocation tests were conducted. Rifampicin $600 \mathrm{mg} /$ day was introduced followed 3 days later by DDS $100 \mathrm{mg} /$ day. Though there were no drug eruptions, including bullous eruption, the patient developed arthralgia and swelling of vestibule and inferior turbinate leading to difficulty in breathing. Investigations including histopathology were essentially similar to that observed at time of presentation. However, the foam cell granulomas had scant lymphocytes, mild fibrosis and $2+$ AFB.

Rifampicin was withdrawn and prednisolone was increased to $60 \mathrm{mg} / \mathrm{day}$, whereupon there was improvement. On reintroduction of rifampicin the patient developed similar symptoms within 24 hours, and thereafter rifampicin was avoided. Introduction of clofazimine $300 \mathrm{mg} /$ day led to moderate improvement. Chloroquine phosphate $250 \mathrm{mg}$ twice daily was introduced in the 12 th week. Over the succeeding 3 weeks there was rapid improvement and the steroids were withdrawn without further deterioration in the clinical state.

\section{Discussion}

Large, tense, histologically subepidermal bullae with deposition of $\operatorname{IgM}, \operatorname{IgG}, \operatorname{IgA}$ and fibrin but no complement along the basement membrane, were confined almost exclusively to leprosy lesions. It was not a drug eruption as provocative tests with rifampicin, clofazimine and DDS did not reproduce bullae. 
Clinically similar bullae occur in bullous pemphigoid (BP), occasionally in dermatitis herpetiformis (DH) and bullous erythema multiforme (EM): None of these occurred coincidentally in this leprosy patient. These have a classical clinical picture and diagnostic immunohistological features. In DH, IgA is deposited at tip of dermal papillae and along the basement membrane ${ }^{4.5}$ In EM iris lesions are pathognomonic, ${ }^{6}$ and the immunologic study may reveal deposits of $\operatorname{IgM}$ and $\mathrm{C}_{3}$ in the walls of the superficial dermal vessels, ${ }^{4}$ but none along the basement membrane. ${ }^{6}$ In $\mathrm{BP}, \mathrm{IgG}$ and $\mathrm{C}_{3}$ are deposited along the basement membrane, ${ }^{4.7}$ Complement $\left(\mathrm{C}_{3}\right)$ deposition occurs in virtually all $\mathrm{BP}$ skin lesions and at times $\mathrm{C}_{3}$ deposit occurs in the absence of $\mathrm{IgG}^{7}{ }^{7}$ Rarely, BP localized to plaques of psoriasis and characterized by deposition of $\mathrm{IgG}$ and $\mathrm{C}_{3}$ along the basement membrane has been observed. ${ }^{8,9}$ In the apparently similar present case there was, however, no deposition of $\mathrm{C}_{3}$.

Bullae can appear in the purpuric, painful, tender, red patches of Lucio phenomenon and in the ENL lesions occurring during Type II leprosy reaction. ${ }^{3}$ None of these two types of lesions were observed in this patient.

Occurrence of bullae during heightened phases of leprosy reaction, firstly, 11 days after start of antileprosy therapy and subsequently during $3 \mathrm{rd}$ and 5 th week of hospitalization when patient was not on antileprosy drugs, along with its strict localization to existing leprosy lesions, suggest that it was an integral concomitant manifestation of leprosy reaction.

The patient initially presented with Type I reaction in BL leprosy which apparently had progressed from borderline tuberculoid (BT). Bullae seemingly appear to be a part of this reaction. Langhans giant cells in macrophage granuloma at the base of bulla can be explained on this basis.

Histopathologically it was not possible to decide whether the bullous reaction represented Type I or Type II. There were large numbers of neutrophils which are often regarded as the hallmark of Type II reaction. But they do occur also in Type I reaction. At times, in $\mathrm{BL}$, no histological distinction between these two types of reactions is possible. ${ }^{10}$ However, there was extravastion of red blood cells and almost near total disappearance of AFB from the granulomas. These are common findings in Type II reactions. Further, deposition of immunoglobulins along the basement membrane, at the edge of bulla indicates an activity of humoral response and Type II reaction is probably immune complex mediated. But, bullae were localized to existing leprosy lesions, and in Type II reactions lesions do not show any change: ${ }^{3}$

Whether this bullous reaction is a variant or a combination of Type I or Type II leprosy reaction is difficult to conclude. Interestingly, it has recently been proposed that ENL is initiated most probably by a cell-mediated response ${ }^{11}$ and is perpetuated perhaps by immune complexes. ${ }^{12}$

\section{Acknowledgment}

The author thanks Dr Indira Nath, Assistant Professor, Department of 
Pathology, AIMS, for her invaluable assistance and guidance. He also thanks Prof U N Bhuyan, Department of Pathology, AIIMS for immunofluorescent evaluations.

\section{References}

I Nigam P, Dayal SG, Goyal BM. Erythema multiforme bullosum due to rifampicin. Lepr India, 1979; 51: 249-51.

2 Dutta RK, Erythema multiforme bullosum due to dapsone. Lepr India, 1980; 52: 306-9.

3 Jopling WH. Leprosy reactions (Reactional states). In: Handbook of Leprosy. London: William Heinemann Medical Books Ltd (2nd ed.), 1978; 66-74.

${ }^{4}$ Lever WF, Schaumburg-Lever G. Non infectious vesicular and bullous diseases. In: Histopathology of the skin. Philadelphia: J B Lippincott Company, 1983; 92-135.

${ }^{5}$ Katz SI, Marks JM. Dermatitis herpetiformis. In: Dermatology in General Medicine. Fitzpatrick TB, Eiren AZ, Wolff et al. (eds), New York: McGraw-Hill Book Company (2nd ed.), 1979; 326-30.

' White JW, Jr. Hypersensitivity and miscellaneous inflammatory disorders. In: Dermatology. Moschella SL, Hurley HJ (eds), Philadelphia: W B Saunders Company (2nd ed.), 1985; 464 98.

7 Jorden RE. Bullous pemphigoid, cicatricial pemphigoid and chronic bullous dermatosis of childhood. In: Dermatology in General Medicine. Fitzpatrick TB, Eiren AZ, Wolff K et al. (eds), New York: McGraw-Hill Book Company (2nd ed.), 1979; 318-23.

${ }^{8}$ Abel EA, Bennett A. Bullous pemphigoid. Occurrence in psoriasis treated with psoralens plus long-wave ultraviolet radiation. Arch Dermatol, 1979; 115: 988-9.

9 Person JR, Rogers III RS. Bullous pemphigoid and psoriasis: does subclinical bullous pemphigoid exist? Brit J Derm, 1976; 95: 535-40.

10 Ridley DS. Reactions, In: Skin Biopsy in Leprosy. Basle: Documenta Geigy, 1977; 47-52.

$"$ Laal S, Bhutani LK, Nath I. The natural emergence of antigen reactive T cells in lepromatous leprosy patients during erythema nodosum leprosy. Infec Immunity, accepted for publication.

12 Mshana RN. Hypothesis: Erythema nodosum leprosum is precipitated by an imbalance of $\mathrm{T}$ lymphocytes. Lepr Rev, 1982; 53: 1-7. 